\title{
The non-medical surgical assistant and inequity in the Australian healthcare system
}

\author{
AUTHORS \\ TONI HAINS RN, MClinSc (PNSA), MNPractSt, PhD \\ Cand. ${ }^{1}$ \\ DAVID ROWELL RN, MHEcon (Advanced), PhD \\ (Econ.) $)^{3}$ \\ HAAKAN STRAND RN, MNPractSt, PhD ${ }^{1,2}$
}

1 The University of Queensland, School of Nursing, Midwifery and Social Work, St Lucia, Queensland, Australia.

2 College of Nursing and Midwifery, Charles Darwin University, Casuarina, Northern Territory, Australia.

3 The University of Queensland, Centre for the Business and Economics of Health, Woolloongabba, Queensland, Australia.

\section{CORRESPONDING AUTHOR}

TONI HAINS School of Nursing, Midwifery and Social Work, Level 3, Chamberlain Building, The University of Queensland, St Lucia QLD 4072. Phone: +61 405469 463. Email: toni@hains.com.au

\section{ABSTRACT}

Objectives: The objective of this discussion paper is two-fold. The first is to quantify if the non-medical surgical assistant increases access to surgery by investigating what percentages of cases these clinicians undertake in the private sector surgical units where they work. The second is to examine procedural and distributive justice and how they impact on private sector surgical care.

Aim: The aim of this paper is to investigate if the non-medical surgical assistant increases equity via access, for the patient, to private sector surgical care; and if government policy has an impact on equity in the form of access.

Background: The private healthcare sector completes approximately two-thirds of all elective surgery in Australia; without this contribution, there would be more pressure on the public healthcare sector. In the private sector, recognition and federal funding of the surgical assistant differs depending on whether this clinician has a medical or non-medical, eg. nursing, qualification. The role of the non-medical surgical assistant is well established internationally and this role has been practiced in Australia for more than 20 years.
Discussion: Inequity; as a result of the procedural injustice of government funding policy, impacts the private sector surgical patient causing distributive injustice. This distributive injustice results in an out-of-pocket expense to the patient. Rising outof-pocket expenses has started a trend of patients moving away from private health insurance and into the public sector. The registered nurse and nurse practitioner are qualified to practise as a non-medical surgical assistant and provide increased access to care, and effective care compared to the medical surgical assistant. The nurse practitioner is an eligible provider of Medical Benefits Schedule services but restricted from accessing the intraoperative assisting item numbers.

Conclusion: The non-medical surgical assistant; or at least the nurse practitioner as non-medical surgical assistant; require access to the Medical Benefits Schedule intraoperative item numbers. Access would alleviate the out-of-pocket expense incurred by Australian patients when a non-medical surgical assistant assists with their surgery. Lack of access to these item numbers means patients may have their surgery delayed until an appropriately skilled medical surgical assistant is available, or the public healthcare sector can accommodate them. 
Implications for research, policy and practice:

This paper illustrates a need for change in Australian government policy to reflect contemporary, evidencebased practice.

What is already known about the topic?

- The international literature reports that advanced practice nursing roles increase access to healthcare.

- The nurse practitioner role in Australia is now well established, and the Australian literature illustrates increased access to care.

- The Medical Benefits Schedule Review Taskforce was formed to investigate a system that is not consistent with contemporary, evidence-based healthcare.
What this paper adds:

- The nurse practitioner and registered nurse, in the role of non-medical surgical assistant, increase access to private sector surgical care.

- Australian government policy limits access to private sector surgical care through its inequitable policies that contravene the spirit of fair trade.

- According to peak professional bodies' policy and position statements, the nurse practitioner and registered nurse are legitimate providers of surgical assisting services.

Key Words: Australian private healthcare sector, nurse practitioner, Australian government health policy, procedural justice, health insurance, distributive justice

\section{INTRODUCTION}

Whether due to political policy, social differences, geographical location or the ability to economically fund care; inequity in healthcare is an unfortunate, but persistent, division in the promotion of social justice. ${ }^{1}$ This paper investigates inequity, in Australia for both patients and clinicians considering the principles of justice and access. ${ }^{2}$ The two types of justice of interest are distributive justice (sometimes called economic justice) which addresses fairness regarding decision outcomes and advocates that equal work should equate to equal pay. ${ }^{3}$ The second is procedural justice which refers to fairness about how decisions or policies are made and suggests that decisions should be fair and based on fact. 4,5

The objective of this paper is two-fold. The first is to quantify if the non-medical surgical assistant (NMSA) increases access to surgery by investigating what percentages of cases these clinicians undertake in the private sector surgical units where they work. The second is to examine procedural and distributive justice and how they impact on private sector surgical care. Figure 2 illustrates the salient points of this argument.

The aim of this paper is to investigate if the NMSA increases equity via access, for the patient, to private sector surgical care; and if government policy has an impact on equity in the form of access. This topic of equity and the NMSA sits within a larger body of research investigating the NMSA in Australia from the perspective of effectiveness, legitimacy, and equity. These three descriptors form part of the conceptual framework of the pillars of quality, as outlined by the father of quality in healthcare, Avedis Donabedian. ${ }^{6-8}$ The relevance of Donabedian's pillars of quality was illustrated in the United States of America (USA) in 1990 when the Institute of Medicine released two reports known as the Quality Chasm
Series. The individual reports were, "To Err is Human: Building a Safer Health System" and "Crossing the Chasm of Quality",,10 These reports were pivotal in moving the conversation regarding quality in healthcare into the mainstream media, the corporate forum and, most importantly, into public healthcare policy. Donabedian's conceptual framework of the pillars of quality was the source material for these reports which investigate the provision of care that is safe, effective, appropriate, equitable and optimises the healthcare dollar. ${ }^{10,11}$

Donabedian's pillars of quality are relevant to the Australian healthcare system as they align with the Australian government's commitment to delivering healthcare that is consumer centred, driven by information, and organised for safety ${ }^{12}$; informed by the objectives of the Australian Government's strategic framework of achieving a safe, equitable, effective and sustainable health system. ${ }^{13}$

Previous research has quantified that the NMSA is a safe and effective provider of surgical assisting care using the comparator of the medical surgical assistant (MSA).14 Similarly, it has been established, through surveys of key stakeholders, the examination of peak professional bodies' position statements and a review of the law that the nurse practitioner (NP) and registered nurse (RN) are legitimate clinicians to perform the role of NMSA in Australia..$^{15-17}$

Due to inequity in the delivery of healthcare many first-world countries currently report differing access to healthcare. ${ }^{18,19}$ In the United States of America (USA) the National Advisory Council on Nursing Education and Practice said that a diverse nursing workforce is essential for the development of equity in healthcare. The need for diversity in the nursing workforce is supported by the notion that advanced practice nurses (APNs) improve the quality and accessibility of care which increases patient satisfaction. ${ }^{20}$ 
The Australian literature informs that the APN and NP enhance access to healthcare. ${ }^{21-28}$ Nurse Practitioners were first endorsed in Australia in 2001. To date some 1,839 NPs practice in Australia, however, despite being eligible providers with access to the Medical Benefits Schedule (MBS), NPs in the private sector of the Australian healthcare system are only able to access four consultation, six telehealth, and no procedural MBS item numbers. ${ }^{29,30}$ This significantly curtails NP private practice. 22,30

As many patients have multi-morbidities, medical care is increasingly complex, and even routine surgical procedures can involve significant risks. The optimal surgical team should be assembled for all surgical procedures. Surgical assistants work closely with the principal surgeon to maximise safety and efficiency. Surgical assistants are an essential part of the surgical team and make a vital contribution to the high standards of surgery available to Australian patients. ${ }^{31}$

Historically surgical assisting in Australia has been undertaken by medical practitioners called medical surgical assistants (MSA). These clinicians are readily available in the public healthcare sector in the form of doctors-intraining. Medical surgical assistants in the private sector are either doctors whose only role is a surgical assistant or general practitioners (GP) who work a dual role. ${ }^{32}$ General practitioners that work a dual role may be unavailable for urgent or emergency procedures; similarly, as specialtyspecific, surgical techniques evolve a specialist assistant may be required.

The NMSA is a clinician who is not a medical practitioner, who provides care to the perioperative patient. In Australia, the role of the NMSA is predominately undertaken by an $\mathrm{RN}$ or the NP. ${ }^{33}$ This role has been practised in Australia for more than 20 years, and RNs and NPs who practice as NMSA

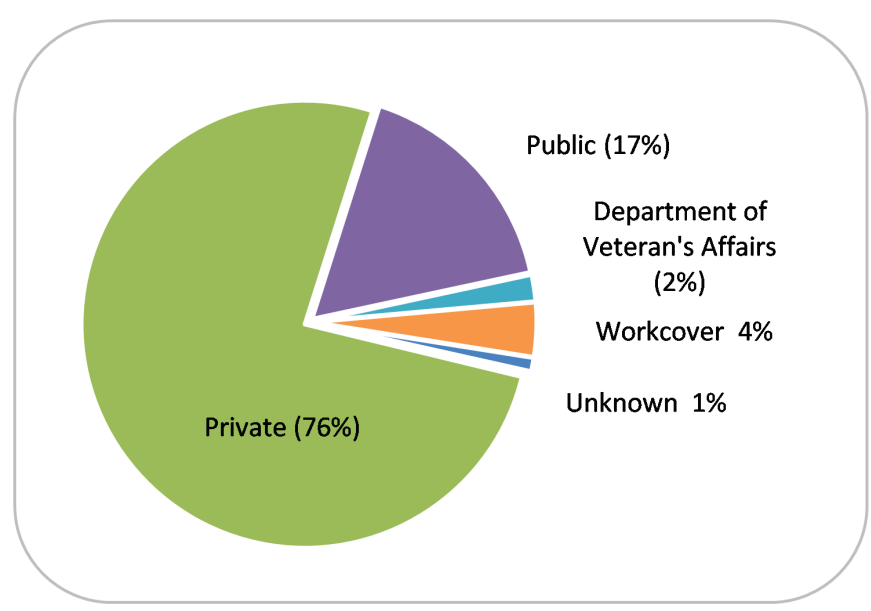

FIGURE 1A: NON-MEDICAL SURGICAL ASSISTANT PROCEDURES BY PATIENT TYPE IN 2016.

Source: Constructed with data from, and permission of, the Australian Association of Nurse Surgical Assistants. ${ }^{38}$ fulfil the requirements of peak professional bodies to act as a surgical assistant. ${ }^{34}$ Brennan suggested in 2001 that the advanced practice of perioperative nurses as surgical assistants could provide cost-effective patient care in the Australian healthcare system. 35 Supporting this; a 2011 Parliamentary research paper investigating "What are we doing to ensure the sustainability of the health system?" suggested investigating role substitution from the medical practitioner to the NP could be a potential cost-saving strategy. ${ }^{36}$

All MSAs within the private sector of the Australian healthcare system have access to surgical assistant MBS item numbers. ${ }^{37}$ The MBS is for the payment of services for the patient. Access for the MSA means the patient is entitled to a rebate for the MSAs' intraoperative services. Currently, only MSAs can access a surgical assistant MBS rebate. Lack of access to the MBS for the NMSA is not an issue of the NMSA not being paid enough due to lack of an MBS rebate; it is an issue of the NMSA (in some cases) not being paid at all. The broader point is the distributive injustice of MBS funding not being available to all clinicians who are qualified to perform a role. Distributive injustice is not restricted to the NMSA but affects many NPs in other specialities of private practice in Australia. ${ }^{30}$

Regarding the NMSA, the process of allowing access to the MBS is a cost-neutral exercise for the government and private health insurers; as an MSA or an NMSA is used, not both. The NMSA would cost the same as the MSA if given access to the current MBS surgical assistant item numbers. Initially, the role of the NMSA evolved because it was sometimes difficult for a surgeon to obtain an MSA for procedures in the private sector. ${ }^{16}$ However, some surgeons choose to use an NMSA due to the specialised nature of particular surgery. Examples of this are cardiac surgery or robotic surgery, which requires specialised skills. ${ }^{32}$

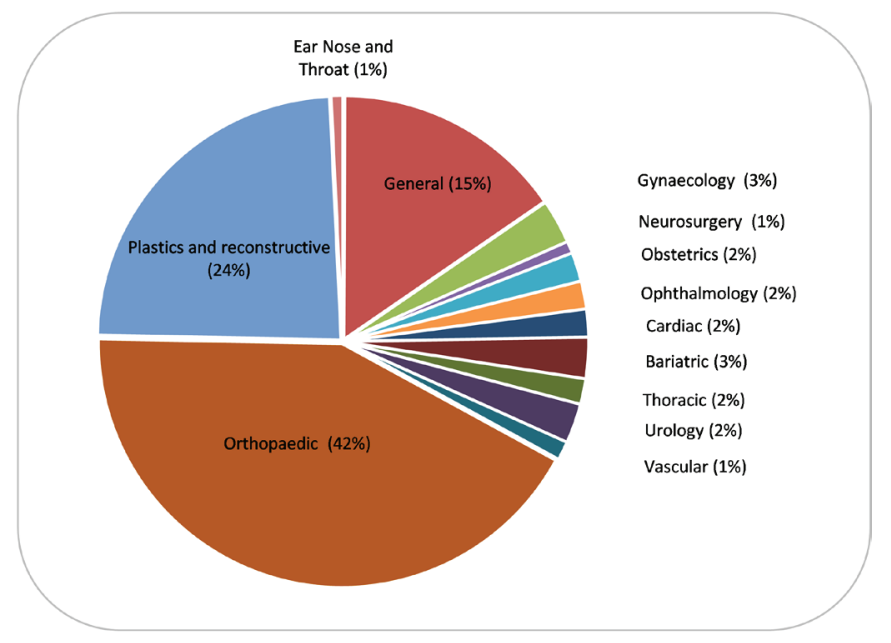

FIGURE 1B: NON-MEDICAL SURGICAL ASSISTANT PROCEDURES BY SURGICAL SPECIALTY IN 2016.

Source: Constructed with data from, and permission of, the Australian Association of Nurse Surgical Assistants. ${ }^{38}$ 
Due to doctors in training in the public sector, the role of the NMSA is predominately within the private sector. ${ }^{15,16,33}$ In $2016,76 \%$ of operations supported by NMSAs took place within the private sector across a range of surgical specialties. ${ }^{2}$ See Figure $1 \mathrm{a}$ and $\mathrm{1b}$

\section{THE FOUR TIERS OF INEQUITY}

Figure 2 uses a hierarchical pyramid model to illustrate how the relationships between inequitable access, remuneration and costs, can ultimately interact to affect the attainment of equity for NMSAs and their patients in the Australian healthcare system.

\section{INEQUITABLE ACCESS}

Access is a term used in academic literature and government policy to describe the receipt of treatment. This concept is underpinned by an individual's medical condition and not their ability to pay. ${ }^{1}$ For this reason, the Australian healthcare system has a public and private sector. The public healthcare sector services patients who are unable to pay for care. The median waiting time for a surgical procedure in the public sector in 2016-17 was 38 days; however, if the surgery was non-life threatening (elective), e.g. total hip replacement the median waiting time was 250 days. Due to private health insurance, $67 \%$ of all elective surgery in Australia is performed in the private sector. ${ }^{39,40}$ By Australians investing in private health insurance, there are shorter waiting times in the public sector and less demand on public sector beds. ${ }^{40}$

Due to the nature of the system, waiting times are not readily available for the private sector; however, they are reported to be shorter than in the public sector. ${ }^{41}$ Securing an MSA for procedures in the private healthcare sector can be difficult. In a survey of Australian surgeons in 2015-2016, 27.5\% revealed they had postponed or cancelled cases as an appropriate surgical assistant was not available. Further, 22.7\% of surgeons said it was difficult or very difficult to secure a surgical assistant, irrespective of their geographical location, for urgent or emergency private sector procedures. ${ }^{16}$

In this situation, the NMSA can increase access to surgery; however, the current lack of government remuneration can restrict this access. An example of this is the Department of Veteran's Affairs (DVA) patient. Access to surgery is limited as the DVA patient does not pay out-of-pocket expenses in the private sector. This means if an MSA is unavailable, the DVA patient may have their procedure postponed until an appropriately skilled MSA is available instead of using an NMSA and paying an out-of-pocket expense.

A situation which illustrates increased access occurred when a group of NMSAs fulfilled the role of surgical assistant for a contract of 110 public beds in a private sector hospital. ${ }^{42}$ Cost and availability rendered the MSA, not a feasible option. The six operating theatre unit was regional, and the NMSA also fulfilled the role of surgical assistant for many private, surgical patients. 43

Inequitable access to surgery exists in many regional centres. Similar to Canada, Australia struggles with doctor shortages outside of metropolitan areas. ${ }^{44}$ While the government has a migration program to procure overseas trained doctors (some of whom may act as an MSA) to regional areas, this program has failed due to cultural difficulties; and lack of training for overseas doctors to function in regional and remote areas without significant support. 45 To demonstrate how the NMSA increases access to surgery in private sector regional Australia, data from four regional hospitals, defined by postcodes ${ }^{46}$ was collected over three months from 1 April 2018 - 30 June 2018 (see Table 1 ).

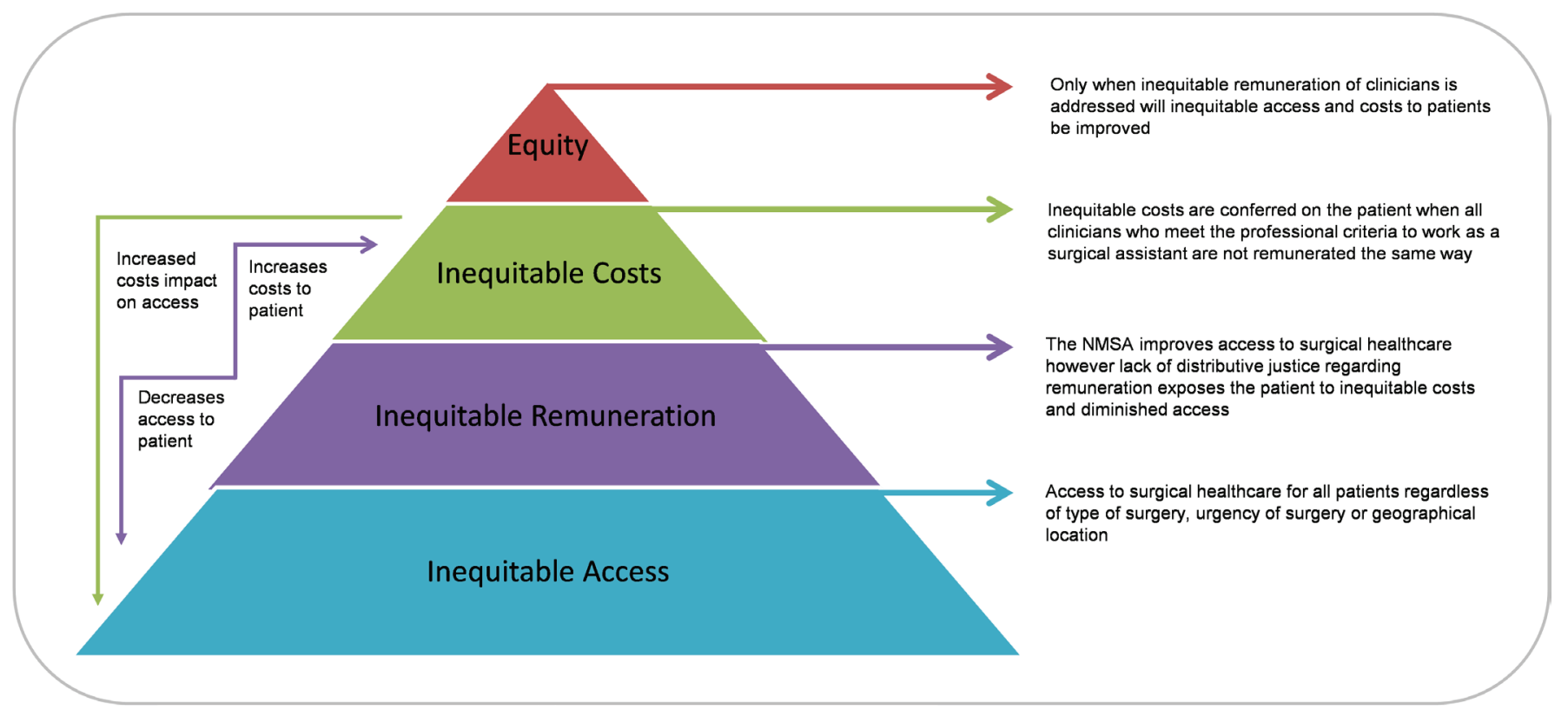

FIGURE 2: PYRAMID OF INEQUITY: AUSTRALIAN NON-MEDICAL SURGICAL ASSISTANTS AND PATIENTS. 
TABLE 1: REGIONAL HOSPITALS SURGICAL ASSISTANT BREAKDOWN (THREE MONTH PERIOD 1 APRIL 2018 - 30 JUNE 2018).

\begin{tabular}{|c|c|c|c|c|}
\hline Surgery Type* & $\begin{array}{l}\text { Hospital } 1 \text { - } \\
190 \text { bed facility }\end{array}$ & $\begin{array}{l}\text { Hospital } 2 \text { - } \\
137 \text { bed facility }\end{array}$ & $\begin{array}{l}\text { Hospital } 3 \text { - } \\
200 \text { bed facility }\end{array}$ & $\begin{array}{l}\text { Hospital } 4 \text { - } \\
16 \text { bed facility }\end{array}$ \\
\hline General & $\begin{array}{l}\text { Total Cases - } 186 \\
\text { MSA - } 120(64.5 \%) \\
\text { NMSA - } 66(35.5 \%)\end{array}$ & $\begin{array}{l}\text { Total Cases - } 273 \\
\text { MSA - } 173(63.37 \%) \\
\text { NMSA - } 20(7.33 \%) \\
\text { Nil }-80(29.30 \%)\end{array}$ & $\begin{array}{l}\text { Total Cases - } 811 \\
\text { MSA - } 407(50.19 \%) \\
\text { NMSA - } 330(40.96 \%) \\
\text { Nil - } 74(9.12 \%)\end{array}$ & \multirow[t]{8}{*}{$\begin{array}{l}\text { Breakdown of } \\
\text { specialties not available }\end{array}$} \\
\hline Orthopaedic & $\begin{array}{l}\text { Total Cases - } 247 \\
\text { MSA - } 83(33.6 \%) \\
\text { NMSA - } 164(66.4 \%)\end{array}$ & $\begin{array}{l}\text { Total Cases - } 218 \\
\text { MSA - } 131(60.09 \%) \\
\text { NMSA - } 67(30.74 \%) \\
\text { Nil - } 20(9.17 \%)\end{array}$ & $\begin{array}{l}\text { Total Cases - } 913 \\
\text { MSA - } 349(38.22 \%) \\
\text { NMSA - } 535(58.6 \%) \\
\text { Nil - } 29(3.18 \%)\end{array}$ & \\
\hline Gynaecology/Obstetric & $\begin{array}{l}\text { Total Cases - } 93 \\
\text { MSA - } 52(55.9 \%) \\
\text { (Caesars } 37 \%) \\
\text { NMSA - } 41(44.1 \%) \\
\text { (Caesars 63\%) }\end{array}$ & $\begin{array}{l}\text { Total Cases - } 87 \\
\text { MSA - } 27(31.04 \%) \\
\text { NMSA - } 21(24.14 \%) \\
\text { Nil - } 39(44.82 \%)\end{array}$ & $\begin{array}{l}\text { Total Cases }-22 \\
\text { MSA - } 7(31.82 \%) \\
\text { NMSA - } 0(0 \%) \\
\text { Nil - } 15(68.18 \%)\end{array}$ & \\
\hline Urology & $\begin{array}{l}\text { Total Cases - } 4 \\
\text { MSA - } 2(50 \%) \\
\text { NMSA - } 2(50 \%)\end{array}$ & $\begin{array}{l}\text { Total Cases }-302 \\
\text { MSA - } 4(1.33 \%) \\
\text { NMSA - } 6(1.99 \%) \\
\text { Nil - } 292(96.68 \%)\end{array}$ & $\begin{array}{l}\text { Total Cases - } 307 \\
\text { MSA - } 28(9.12 \%) \\
\text { NMSA - } 0(0 \%) \\
\text { Nil - } 279(90.88 \%)\end{array}$ & \\
\hline Plastic/Reconstructive & $N / A$ & $\begin{array}{l}\text { Total Cases - } 118 \\
\text { MSA - } 11(9.32 \%) \\
\text { NMSA - } 1(0.85 \%) \\
\text { Nil - } 106(89.83 \%)\end{array}$ & $N / A$ & \\
\hline Ear, Nose and Throat & $\begin{array}{l}\text { Total Cases - } 11 \\
\text { MSA - } 0(0 \%) \\
\text { NMSA - } 0(0 \%) \\
\text { Nil - } 11(100 \%)\end{array}$ & $\begin{array}{l}\text { Total Cases - } 127 \\
\text { MSA - } 32(25.20 \%) \\
\text { NMSA - } 0(0 \%) \\
\text { Nil - } 95(74.80 \%)\end{array}$ & $\begin{array}{l}\text { Total Cases - } 360 \\
\text { MSA - } 0(0 \%) \\
\text { NMSA - } 0(0 \%) \\
\text { Nil - } 360(100 \%)\end{array}$ & \\
\hline Robotic & $\mathrm{N} / \mathrm{A}$ & $\begin{array}{l}\text { Total Cases - } 16 \\
\text { MSA - } 0(0 \%) \\
\text { NMSA - } 16(100 \%)\end{array}$ & $\begin{array}{l}\text { Total Cases - } 12 \\
\text { MSA - } 12(100 \%) \\
\text { NMSA - } 0(0 \%)\end{array}$ & \\
\hline Cardiothoracic/Vascular & $\mathrm{N} / \mathrm{A}$ & $\begin{array}{l}\text { Total Cases - } 55 \\
\text { MSA - } 8(14.55 \%) \\
\text { NMSA - } 0(0 \%) \\
\text { Nil - } 47(85.45 \%)\end{array}$ & $\begin{array}{l}\text { Total Cases - } 59 \\
\text { MSA - } 56(94.92 \%) \\
\text { NMSA } 3(5.08 \%)\end{array}$ & \\
\hline Total procedures & 1,198 & 2,179 & 2,484 & 530 \\
\hline Procedures requiring an assistant & 530 & 517 & 1727 & 113 \\
\hline NMSA assistant \% & $51.50 \%$ & $25.33 \%$ & $50.26 \%$ & $56.63 \%$ \\
\hline
\end{tabular}

Permission to access data was received from each hospital and data was retrieved from the electronic hospital records

* Surgical procedures performed in theatre but not requiring an assistant at these hospitals ie. Endoscopy, Dental, Electroconvulsive therapy (ECT), Cardioversion and Pain procedures etc. are not listed. ${ }^{\star}$ Surgical procedures performed in theatre but not requiring an assistant at these hospitals

Of note here is that some of the private surgical procedures in this data are unavailable in the public hospitals in these regions. This means patients without private health insurance or unable to pay out-of-pocket expenses for the NMSA, would need to travel to a metropolitan hospital to receive their surgery. This is costly for the patient, may cause delays for their procedure and potentially compounds public-sector pressure.

In Hospital 1, the NMSA assisted for 51.5\% of cases, in Hospital 2 , the NMSA assisted for $25.3 \%$ of cases. Hospital 1 and 2 represent all private surgery undertaken in a regional town with a population of approximately 115,000 . The NMSA assisted for $38.5 \%$ of all private surgery in this town, carried out during the data collection period. Surgeons, in this region, are also training the NMSAs to assist for Robotic surgery as this will provide a consistent service. The NMSA assisted with more Caesarean Sections; often an urgent procedure conducted out-of-hours. The NMSA assisted for $63 \%$ compared to the MSA who assisted for $37 \%$.

Hospital 2 has records of perioperative staff, i.e. scrub and scout staff, acting as a surgical assistant for some of the procedures. It is anticipated that this practice occurs in many hospitals. This practice is contrary to the Clinical Guidelines of the Australian College of Operating Room Nurses and exposes these non-designated staff to medico-legal consequences should patients experience intraoperative or postoperative complications. ${ }^{15}$ In a recent survey of perioperative staff, 17\% said they performed the impromptu role of surgical assistant daily, and $18.7 \%$ performed the position once a week..$^{15}$ The practice of improvised use of perioperative staff as surgical assistants, coupled with the fact that an NMSA assisted for a quarter of the surgery conducted at this hospital reinforces the notion that a need exists in Australian for the NMSA. 
In Hospital 3, the NMSAs assisted for more than $50 \%$ of the orthopaedic procedures. For this hospital, orthopaedic procedures represented over a third of all surgical procedures for the data collection period.

Hospital 4 is located in a regional town with a population of 42,000 and is the only private hospital in the area. Mainly operating on day procedures, the hospital has a 16-bed capacity. Over 50\% of procedures needing a surgical assistant, were undertaken by the same single NMSA.

As was evident at the inception of the role of the NP in Australia, advanced practice nurses are one strategy to improve access to medical services in regional or rural Australia yet they lack the private sector remuneration to sustain this. ${ }^{28,47-50}$

\section{INEQUITABLE REMUNERATION VIA AN MBS PATIENT REBATE}

According to peak professional healthcare organisations (Royal Australasian College of Surgeons, The Australian College of Operating Room Nurses, The Australian College of Nurse Practitioners, and The Australian Association Nurse Surgeon's Assistants) the NP and RN are legitimate clinicians to undertake the role of NMSA.34,51-53 Similarly, the Australian Health Professional Regulation Agency (AHPRA) does not specify any requirements or place any limitations on which clinicians can undertake the role of a surgical assistant. However, in the private sector, Medicare via the MBS will only remunerate the medical practitioner as a surgical assistant. ${ }^{54}$ Medicare is not the law but the government's interpretation of the law. 55 Given this, the government can alter the MBS rules as they see necessary. The rules that exclude the NMSA to funding is not a discrete issue of private sector funding but a broader issue of distributive justice which advocates equal work should equate to equal pay. ${ }^{3}$ The concept of distributive justice also leads to the notion of anti-competitive restriction of activity that some professionals have benefited from since the creation of the MBS in $1975 .{ }^{.6}$

According to the Australian Government's website on the topic, "Fair Trading" is Australian commonwealth and state/ territory laws that protect the worker, their business and their customers from unfair trading practices. ${ }^{57}$ The role of the Australian Competition and Consumer Commission (ACCC) is to uphold fair trading, encourage competition and regulate national infrastructure..$^{8}$ Paragraph six of the ACCC website elaborates that, Competitive, informed and (when necessary) well-regulated markets lead to lower prices, better quality products and services, and more choice. This increases the prosperity and welfare of all Australians. The ACCC takes action to improve consumer safety, protect competition or stop conduct that is anti-competitive or detrimental to consumers..$^{8}$

As the NMSA cannot access the MBS for an assisting rebate for patients, a lack of distributive justice for both the NMSA and their patient is demonstrated. This would appear not to protect the worker who may not be paid if the patient reneges on the out-of-pocket. The out-of-pocket expense causes financial harm to the consumer of the surgical service, a form of procedural injustice due to government policy. Additionally, physical harm may come to the patient who cannot pay the out-of-pocket and therefore may have to wait for their surgery. Delayed surgery increases hospital length of stay and complication rate. ${ }^{59}$ Anti-competitive MBS rules supported by the government allows the MSA a monopoly on access to the MBS for surgical assisting services.

Similar to the MSA, the NMSA must satisfy credentialing requirements at each clinical site where they practice and; specific to NP, have a collaborative agreement with a surgeon which includes a surgical assistant scope of practice. The NP also has an MBS Provider Number yet is denied access to the surgical assistant Item Numbers. However, there are international and Australian data that demonstrates the NMSA has equivalent patient outcomes to the MSA. ${ }^{14,58-63}$ Patient outcomes investigated in the Australian data considered six dependent variables; time in the operating theatre, intraoperative time, admission to Intensive Care, length of stay, discharge destination and readmission within 28 days. The results showed no statistically significant difference and no clinically relevant difference between the MSA and NMSA. ${ }^{14}$

While the RN working as an NMSA satisfies hospital credentialing and peak professional bodies' criteria; the NP offers those in government an uncomplicated opportunity to regulate the role of the NMSA. The NP model of care has a principal goal of improving access to high-quality care, yet provisions under the MBS for this eligible provider have not been reviewed regarding relevance to the patient and functionality of the role for a decade.22 As Bryant outlined, combining the NMSA and NP roles achieves:

1. Standardised education - with a Master's Degree approved by the Nursing Midwifery Board of Australia;

2. National competencies, ie. Standards for Practice;

3. Identification on the AHPRA register separate to Registered Nurses; and

4. Title protection ${ }^{60}$

Nurse Practitioners working in the private sector of the Australian healthcare system are an underused resource and remain curtailed by the small number of MBS Items for which the patient receives a rebate. While patients support healthcare delivered by the NP, limited access to the MBS for NPs increases costs borne by the patient and reduces accessibility to private NP care. ${ }^{25,61-63}$ A practice audit of clinicians in the role of NMSA in Australia, revealed that all NPs in the NMSA role but one possessed a NMSA qualification in addition to their Nursing and Midwifery Board of Australia recognised Master's Degree. ${ }^{33}$ 


\section{INEQUITABLE COSTS}

The Australian Government was predicted to spend $\$ 87.9$ billion on health in 2017-18. ${ }^{64}$ Approximately $47 \%$ of the Australian population chooses to also pay for private health insurance in addition to the assurance offered by Medicare. ${ }^{65}$ In 2014-15, 4.5 million of the 10.6 million admissions to public (14\% of admissions to public hospitals) and private hospitals ( $83 \%$ of admissions to private hospitals) were funded by private health insurance. ${ }^{39}$ It is essential to the functioning of the public healthcare sector that Australians maintain their private health insurance and utilise the private healthcare sector for surgical procedures, however; due to rising costs of health insurance premiums and an additional overall 3.3\% rise in out-of-pocket expenses, the number of Australians with private health insurance dropped by $0.9 \%$ from June 2017 June 2018.39

Patients in the private sector of the Australian healthcare system pay taxes to Medicare and private health insurance premiums to cover the costs of their care while undergoing surgical procedures in the private sector. These costs include the payment of a rebate to the patient for the surgical assistant. Topical in Australia at the moment is the significant out-of-pocket expenses that the patient incurs from private clinicians such as surgical assistants who charge the patient a gap above the rebate they receive for services related to surgery. ${ }^{32,66}$ While the MSA may choose to charge the patient an out-of-pocket expense in addition to the rebate they receive; the NMSA charges an out-of-pocket fee as their only form of payment.

The surgeon will use an MSA or an NMSA; the NMSA is not a duplication of services for the healthcare sector but is a duplication of payment for the patient who has already paid their taxes and health insurance premiums and must also pay an out-of-pocket expense for the NMSA's clinical services. In these circumstances, the patient is being exposed to procedural injustice by the Commonwealth Government who sets the rules for the MBS. ${ }^{37}$ The definition of procedural justice states that decisions should be fair and based on fact. ${ }^{4}$ Limiting access to the MBS assisting Item Numbers is not fair, and as the NMSA has equal patient outcomes to the MSA, this limitation is not based on fact.

The MBS Review Taskforce is currently evaluating "Proposed changes to remuneration arrangements for surgical assistants" and released a document on 4 September 2018 for stakeholder consultation. The proposal is to change the process for the remuneration of those with access ("medically qualified") to the Assistance at Operations Item Numbers TN9.1. 5130051318. While this document does not outline the NMSA as an alternative to the MSA, it has created an opportunity for peak professional bodies to suggest the NMSA as an eligible provider of this service.

The MBS Review Taskforce has also released a document, "Report from the Nurse Practitioner Reference Group 2018" for stakeholder consultation on 6 February 2019. This report outlines 14 recommendations. Eight of the recommendations focus on increased access to the MBS for patients treated by the NP. Recommendation 10 says, "Enable patients to access MBS rebates for procedures performed by an NP."22 Neither of these processes was finalised at the time of publication of this paper in 2020.

\section{CONCLUSION}

Government policies negatively impact on the private sector surgical patient, when the NMSA does not have access to the MBS surgical assisting item numbers. This lack of procedural justice afforded to patients to achieve improved health through private sector surgery limits the access or causes an extra financial burden.

There has been a consistent move away from patients investing in private health insurance, due partly to the cost of insurance premiums and secondly to large out-of-pocket expenses. A move away from private health insurance increases the waiting times in the public healthcare sector. ${ }^{67}$ Those patients who make the financial sacrifice to invest in private health insurance are penalised by government policy restricting a rebate for some clinician's clinical services.

In the context presented here, access to surgery for the patient in the private sector is most limited when the operation is highly specialised needing an experienced surgical assistant; when the procedure is urgent or an emergency; or when the procedure is in a regional location. Access is limited when no MSA is available, and the patient cannot pay the out-of-pocket expense for the NMSA.

As outlined in the MBS Review Taskforce - Report from the Nurse Practitioner Reference Group, "Inequity in funding mechanisms should not prevent people from receiving comprehensive, evidence-based care".22 The lack of distributive justice imposed on the NMSA and particularly the NP as an eligible MBS provider does not reflect contemporary NP practice. The question here is not "should NPs be undertaking this role?" but "why are NPs not funded when undertaking a role for which they meet the professional criteria?" Until the NMSA; or a least the NP as an NMSA; is given access to the MBS assisting item numbers patients will continue to have restricted access, be economically penalised or have their surgery delayed until an appropriately skilled MSA is available or the public healthcare sector can accommodate them.

\section{RECOMMENDATIONS}

The Australian government is committed to achieving a safe, equitable, effective and sustainable health system, but this is not happening. ${ }^{13}$ Likewise, it was the MBS Review Taskforce's mission to align the MBS to contemporary healthcare practice. This has not occurred in relation to the NMSA. 
To allow patients equitable access to private sector surgical care, the MBS must align with contemporary perioperative practice. While access to all RNs and NPs in the role of NMSA would enhance patient access to surgery; as a minimum, the Australian government via the MBS must enable the NP to access the Category 3 TN.9.1 51300-51318 surgical assistant item numbers.

\section{Funding: Nil}

Declaration of competing interests: This paper forms part of a thesis to be submitted for examination for a Doctor of Philosophy degree in the School of Nursing, Midwifery and Social Work; at the University of Queensland.

\section{REFERENCES}

1 Wagstaff A, van Doorslaer E. Chapter 34 Equity in health care finance and delivery. Handbook of Health Economics. 1: Elsevier; 2000. p. 1803-62

2 Health and Community Services Workforce Council. Fact sheet: social justice and health. Queensland Government. 2013. Available from: https://www.checkup.org.au/icms docs/182820 15 FACTSHEET Social Justice and Health.pdf.

3 Jordan A. Distributive Justice: definition, theory, principles \& examples. 2019. Available from: https://study.com/academy/ lesson/distributive-justice-definition-theory-principlesexamples.html.

4 Schofield T. Procedural justice in the workplace: definition, theory \& examples. 2019. Available from: https://study.com/ academy/lesson/procedural-justice-in-the-workplace-definitiontheory-examples.html.

5 Fondacaro M, Frogner B, Moos R. Justice in health care decision-making: patients' appraisals of health care providers and health plan representatives. Soc Justice Res. 2005; 18(1):63-81.

6 Ayanian JZ, Markel H. Donabedian's lasting framework for health care quality. N Engl J Med. 2016; 375(3):205-7.

7 Marjoua Y, Bozic KJ. Brief history of quality movement in US healthcare. Curr Rev Musculoskelet Med. 2012; 5(4):265-73

8 Donabedian A. The seven pillars of quality. Arch Pathol Lab Med. 1990; 114(11):1115-8

9 Institute of Medicine. To err is human: building a safer health system. Washington DC: Institute of Medicine; 2000.

10 Institute of Medicine. Crossing the chasm of quality: a new health system for the 21st century. 18th ed. Washington DC: National Academy Press; 2001.

11 Wakefield M. The quality chasm series: implications for nursing In: Hughes R, editor. Patient Safety and Quality: An EvidenceBased Handbook for Nurses. Rockville: Agency for Health Research and Quality; 2008.

12 Australian Commission on Safety and Quality in Healthcare. Australian safety and quality framework for health care putting the framework into action: getting started. Sydney: Australian Commission on Safety and Quality in Healthcare; 2011. p.1.

13 Australian Government. National primary health care strategic framework. Department of Health and Ageing. Canberra. 2013.

14 Hains T, Rowell D, Turner C, Strand H. Effectiveness of the Non-Medical Surgical Assistant measured by patient outcome assessment. Int J Nurs Pract. 2020
15 Hains T, Turner C, Strand H. Knowledge and perceptions of the non-medical surgical ssistant role in Australia - a perioperative staff survey. J Periop Nurs Austr. 2017; 30(3):39-45.

16 Hains T, Turner C, Strand H. Task transfer: a survey of Australian surgeons on the role of the non-medical surgical assistant. J Periop Nurs Austr. 2018; 31(1):11-7.

17 Hains T, Turner C, Gao Y, Strand H. Valuing the role of the nonmedical surgical assistant. Aust N Z J Surg. 2017; 87(4):222-3.

18 Carryer J, Adams S. Nurse practitioners as a solution to transformative and sustainable health services in primary health care: a qualitative exploratory study. Collegian. 2017; 24(6): 525-31.

19 Kooienga SA, Carryer JB. Globalization and advancing primary health care nurse practitioner practice. J Nurs Pract. 2015; 11(8):804-11.

20 Krista J, Kaisa H, Riitta M, Anna-Maija P. Advanced practice nursing roles: the phases of the successful role implementation process. Int J of Caring Sci. 2014; 7(3):946-54.

21 O'Connor M, Palfreyman S, Borghmans F. Reflections on establishing a nurse practitioner role across acute hospital and home-based palliative care settings in Australia. Int J Pall Nurs. 2018; 24(9):436-42

22 Australian Government. Report from the nurse practitioner reference group Medical Benefits Review Taskforce. 2018 Available from: http://www.health.gov.au/internet/main/ publishing.nsf/Content/58EFEA022C2B7C49CA25839600 83C4EA/\$File/v2-NPRG\%20Final\%20Report.

23 Australian College of Nurse Practitioners. Nurse Practitioners a solution to accessible healthcare. Australian College of Nurse Practitioners, 2017.

24 Gardner G, Duffield C, Doubrovsky A, Adams M. Identifying advanced practice: a national survey of a nursing workforce. Int J Nurs Stud. 2016; 55:60-70.

25 Lowe G, Plummer V, Boyd L. Perceptions of NP roles in Australia: nurse practitioners, managers, and policy advisors. J Nurs Pract. 2016; 12(7):e303-e10

26 Lowe G, Plummer $V$, Boyd L. Nurse practitioner roles in Australian healthcare settings. Nurs Manag. 2013; 20(2):28-35

27 Lowe G, Plummer V, O'Brien AP, Boyd L. Time to clarify - the value of advanced practice nursing roles in health care. J Adv Nurs. 2011; 68(3):677-85.

28 National Rural Health Alliance Inc. Advanced nursing practice in rural and remote areas. 2005. Available from: www.ruralhealth.org.au.

29 Nursing and Midwifery Board of Australia. Registrant Data. 2019. Available from: https://www.nursingmidwiferyboard.gov au/About/Statistics.aspx

30 Currie J, Chiarella M, Buckley T. Privately practising nurse practitioners' provision of care subsidised through the Medicare Benefits Schedule and the Pharmaceutical Benefits Scheme in Australia: results from a national survey. Aust Health Rev. 2019; (43):55-61.

31 Bartone T. Response to MBS Review_-Proposed changes to remuneration arrangements for surgical assistants. Australian Medical Association; 2018. Available from: https://www. amansw.com.au/ama-rejects-changes-to-surgical-assistants/

32 Hains T, Turner C, Strand H. Complexities of the Australian perioperative nurse entrepreneur. Austr J Adv Nurs. 2018; 36:1:48-55. 
33 Hains T, Turner C, Strand H. Practice Audit of the Role of the non-medical surgical assistant in Australia, an online survey. Intl J Nurs Pract. 2016; 22(6):546-55.

34 Royal Australasian College of Surgeons. Position Statement Surgical Assistants: Royal Australasian College of Surgeons; 2015. Available from: https://www.surgeons.org/about-racs/ position-papers/surgical assistants.

35 Brennan B. The registered nurse as a first surgical assistant: the "downunder" experience. Semin Periop Nurs. 2001; 10(2):108-14.

36 Boxall A. Research Paper: What are we doing to ensure the sustainability of the health system? 2011. Available from: https://parlinfo.aph.gov.au/parllnfo/download/ library/prspub/1234561/upload binary/1234561. pdf;fileType=application/pdf\#search=\%222010s\%20boxall,\%20 anne-marie\%22

37 Australian Government. Medicare benefits schedule online: note TN.9.1. 2018. Available from: http://www9.health.gov.au/ $\mathrm{mbs} /$ fullDisplay.cfm?type $=$ note\&qt=NotelD\&q=TN.9.1

38 Ballantyne L. Australian Association of Nurse Surgical Assistants Data for 2016. Email recipient Hains T. 13/03/2017.

39 Australian Government. Australia's health 2018: in brief. 2018. Available from: https://www.aihw.gov.au/reports/australiashealth/australias-health-2018/contents/table-of-contents

40 Private Healthcare Australia. Supporting the public system: private healthcare australia. 2020. Available from: https://www.privatehealthcareaustralia.org.au/have-you-gotprivate-healthcare/why-private-health-insurance/supportingthe-public-system/.

41 Willis K, Lewis S. Which are better, public or private hospitals? 2016. Available from: https://theconversation.com/which-arebetter-public-or-private-hospitals-54338.

42 Coghill J. Teething problems hinder new hospital. ABC Sunshine Coast. 2014. Available from: http://www.abc.net.au/local/ stories/2014/04/23/3990656.htm.

43 Smith C, Hains T, Mannion N. An opportunity taken: sunshine coast university private hospital's perioperative nurse surgical assistant experience. J Periop Nurs Austr. 2016; 29(3):23-8.

44 Hooker R, Hogan K, Leeker E. The globalization of the physician assistant profession. J Physician Assist Ed. 2007; 18(3).

45 Borrello E. Calls for government to stop giving visas to overseas-trained doctors to address rural shortage. ABC News. 2016. Available from: https://www.abc.net.au/news/201608-09/calls-to-stop-giving-overseas-trained-doctorsvisas/7706612

46 Australian Government. Postcodes of regional Australia. 2018. Available from: https://immi.homeaffairs.gov.au/visas/gettinga-visa/visa-listing/skilled-regional-provisional-489/regionalpostcodes.

47 Kelly J, Garvey D, Biro M, Lee S. Managing medical service delivery gaps in a socially disadvantaged rural community: a nurse practitioner led clinic. Austr J Adv Nurs. 2017; 34(4):42-9.

48 Francis K, Boyd M, Latham H, Anderson J, Bradley A, Manners $\mathrm{J}$. A regional approach to the education of nurse practitioner candidates to meet the health needs of rural Australians. Contemp Nurs. 2014; 49(1):27-34.

49 Mills J, Lindsay D, Gardner A. Nurse practitioners for rural and remote Australia: creating opportunities for better health in the bush. Austr J Rural Health. 2011; 19(1):54

50 Turner C, Keyzer D, Rudge T. Spheres of influence or autonomy? A discourse analysis of the introduction of Nurse Practitioners in rural and remote Australia. J Adv Nurs. 2007; 59(1):38-46.
51 The Australian College of Operating Room Nurses. Standards for perioperative nursing. nursing role: perioperative nurse surgeon's assistant. 2015.

52 Australian College of Nurse Practitioners. Submission to: (MBS) Review - Proposed changes to remuneration arrangements for surgical assistants. 2018. Letter to chair.

53 Australian Association Nurse Surgeon's Assistants. Scope of practice/ position description. 2012. Available from: http://www.aansa.org.au/f.ashx/PNSA-Position-DescriptionAANSA-2012.pdf

54 Australian Government. MBS Online 2019. Available from: www.mbsonline.gov.au/internet/mbsonline/publishing.nsf/ Content/FAQ-Legislation

55 Faux M, Wardle J, Adams J. Medicare billing, law and practice: complex, incomprehensible and beginning to unravel. J Law Med. 2019; 27:66-93.

56 Wardle J. Defining deviation: the peer professional opinion defence and its relationship to scope expansion and emerging non-medical health professions. J Law Med. 2016; 23(3):662-77.

57 Australian Government. Fair Trading. 2018. Available from: https://www.business.gov.au/products-and-services/fairtrading.

58 Australian Competition and Consumer Commission. About the ACCC. Available from: https://www.accc.gov.au/about-us/ australian-competition-consumer-commission/about-theaccc\#our-role.

59 Lefaivre KA, Macadam SA, Davidson DJ, Gandhi R, Chan H, Broekhuyse HM. Length of stay, mortality, morbidity and delay to surgery in hip fractures. J Bone Joint Surg Brit volume. 2009; 91-B(7):922-7.

60 Bryant E. Perioperative nurse surgeon's assistants in day surgery an emerging role within Australia's health system. Ambulatory Care. 2010; July:25-7.

61 Cashin A. The challenge of nurse innovation in the Australian context of universal health care. Collegian. 2015; 22(3):319-24.

62 Keating SFJ, Thompson JP, Lee GA. Perceived barriers to the sustainability and progression of nurse practitioners. Int Emerg Nurs. 2010; 18(3):147-53

63 Harkless G, Vece L. Systematic review addressing nurse practitioner reimbursement policy: part one of a four-part series on critical topics identified by the 2015 nurse practitioner research agenda. J Am Acad Nurse Pract. 2018; 30(12):673-82.

64 Australian Government. The Australian health system. 2018. Available from: https://beta.health.gov.au/about-us/theaustralian-health-system Australian Government;

65 Jolly W. Australian health insurance statistics. Canstar. 2018 Available from: https://www.canstar.com.au/health-insurance/ who-has-health-insurance/

66 Parliament of Australia. Value and affordability of private health insurance and out-of-pocket medical costs. 2017. Available from: https://www.aph.gov.au/Parliamentary Business/Committees/ Senate/Community Affairs/Privatehealthinsurance: Australian Government

67 Hatch P, McCauley D. Private health system in a 'death spiral', says expert, but what can be done to save it? The Sydney Morning Herald. 2019. Available from: https://www.smh.com. au/business/consumer-affairs/private-health-system-in-adeath-spiral-says-expert-but-what-can-be-done-to-save-it20191128-p53f58.html 